\title{
FLARE STARS IN
}

STAR CLUSTERS,

ASSOCIATIONS AND

THE SOLAR VICINITY

Edited by L. V. MIRZOYAN, B. R. PETTERSEN and M. K. TSVETKOV

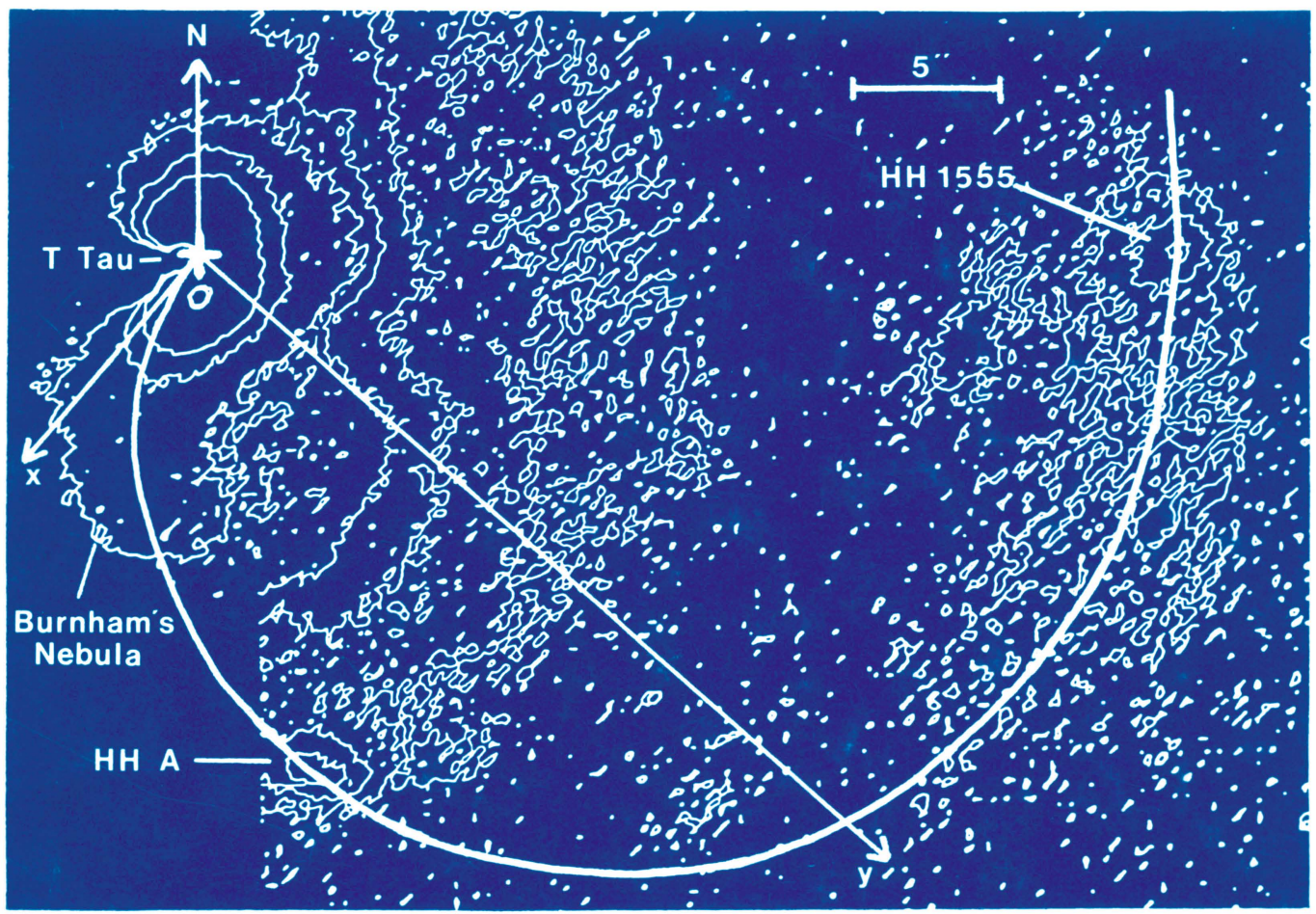

INTERNATIONAL ASTRONOMICAL UNION

KLUWER ACADEMIC PUBLISHERS 
FLARE STARS IN STAR CUSTERS, ASSOCIATIONS AND THE SOLAR VICINITY 


\section{FLARE STARS IN STAR CLUSTERS, ASSOCIATIONS AND THE SOLAR VICINITY}

PROCEEDINGS OF THE 137TH SYMPOSIUM OF THE INTERNATIONAL ASTRONOMICAL UNION

HELD IN BYURAKAN (ARMENIA), U.S.S.R., OCTOBER 23-27, 1989

EDITED BY

L. V. MIRZOYAN

Byurakan Observatory, Armenia Academy of Sciences, U.S.S.R.

B. R. PETTERSEN

Institute of Theoretical Astrophysics, University of Oslo, Norway

and

M. K. TSVETKOV

Department of Astronomy, Academy of Sciences, Bulgaria

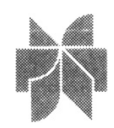

KLUWER ACADEMIC PUBLISHERS

DORDRECHT / BOSTON / LONDON

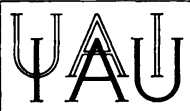


Library of Congress Cataloging in Publication Data

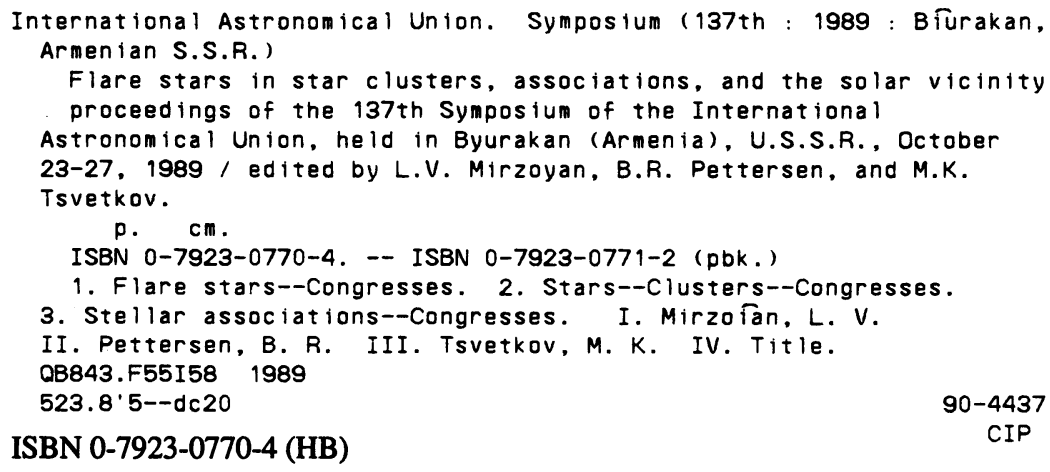

\section{Published on behalf of}

the International Astronomical Union

by

Kluwer Academic Publishers, P.O. Box 17, 3300 AA Dordrecht, The Netherlands.

Kluwer Academic Publishers incorporates the publishing programmes of D. Reidel, Martinus Nijhoff, Dr W. Junk and MTP Press.

Sold and distributed in the U.S.A. and Canada by Kluwer Academic Publishers, 101 Philip Drive, Norwell, MA 02061, U.S.A.

In all other countries, sold and distributed by Kluwer Academic Publishers Group, P.O. Box 322, 3300 AH Dordrecht, The Netherlands.

\section{Printed on acid-free paper}

All Rights Reserved

(C) 1990 by the International Astronomical Union

No part of the material protected by this copyright notice may be reproduced or utilized in any form or by any means, electronic or mechanical including photocopying, recording or by any information storage and retrieval system, without written permission from the publisher.

\section{Printed in The Netherlands}


TABLE OF CONTENTS

Preface $\quad$ xi

List of participants $\quad$ xiii

I. FLARE STARS. OPTICAL OBSERVATIONS AND FLARE STATISTICS.

L.V. MIRZOYAN

Flare stars in star clusters, associations and solar vicinity (Invited paper)

B.R. PETTERSEN, K.P. PANOV, M.S. IVANOVA, C.W. AMBRUSTER, E. VALTAOJA, L. VALTAOJA, S. AVGOLOUPIS, L.N. MAVRIDIS, J.H. SEIRADAKIS, S.R. SUNDLAND, K. OLAH, O. HAVNES, Ó. OLSEN, J.E. SOLHEIM, T. AANESEN

The flare activity of AD Leo 1972-1988

R.E. GERSHBERG, I.V. ILYIN, N.S. NESTEROV, R.G. GETOV, M. IVANOVA, K.P. PANOV, M.K. TSVETKOV, G. LETO

Photometrical, spectral and radio monitoring for EV Lac in 1986 and 1987

A.S. MELKONIAN

Electrophotometric observations of the EV Lac flares in $\mathrm{U}, \mathrm{H} \alpha$ and $\mathrm{H} \beta$

K.P. PANOV, M.S. IVANOVA, A. ANTOV

Rapid spike flares on $A D$ Leo and EV Lac

N.D. MELIKIAN, V.S. SHEVCHENKO

Photoelectric observations of flares on UV Ceti

V.P. ZALINIAN, A.A. KARAPETIAN, H.M. TOVMASSIAN

Two-colour observations of spikes and flares with high time resolution

B.E. ZHILYAEV, Ya.O. ROMANJUK, O.A. SVYATOGOROV

A short-lived flare on EV Lacertae

A.V. BERDYUGIN

Diagnostic possibilities of the Walrawen photometric system

I.V. ILYIN, N.I. SHAKHOVSKAYA

The flare activity of two peculiar red dwarfs

K. ISHIDA

Statistics of flares observed for UV Ceti type stars YZ CMi, $\mathrm{AD}$ Leo, and EV Lac at the Okayama Observatory 
B.R. PETTERSEN

Flare activity levels for fully convective red dwarfs

N.I. SHAKHOVSKAYA

Some physical consequences from the flare statistics of the UV Cet type stars in the solar neighbourhood

N.I. BONDAR

Search for slow light variations of red-dwarf stars

A.T. GARIBJANIAN, V.V. HAMBARIAN, L.V. MIRZOYAN, A.L. MIRZOYAN Distribution of red dwarfs in general galactic field on the basis of stellar star statistics

H.S. CHAVUSHIAN, G.H. BROUTIAN

New observations of flare stars in the Pleiades by the method of stellar tracks

J. KELEMEN

Possible new, bright flare star in the Pleiades region

G. SZÉCSÉNYI-NAGY

Data filtering in statistical studies of flares recorded in sky fields of stellar aggregates - demonstrated with the example of the Pleiades

A.L. MIRZOYAN, M.A. MNATSAKANIAN

On two possible groups of flare stars in Pleiades

A.S. HOJAEV

Flare activity of stars in the Taurus region

R. ANIOL, H.W. DUERBECK, W.C. SEITTER, M.K. TSVETKOV

An automatic search for flare stars in southern stellar

aggregates of different ages

L.V. MIRZOYAN, V.V. HAMBARIAN, A.T. GARIBJANIAN

Spectral observations of flare stars

H.W. DUERBECK, M.K. TSVETKOV

NTT spectra of the flare stars HM1 and HM2 in the $R$ Coronae

Austrinae aggregate

R.Sh. NATSVIISHVILI

Catalog of flare stars in orion nebula region

M.K. TSVETKOV, K.P. TSVETKOVA

A catalogue of flare stars in the Cygnus region 
E.S. PARSAMIAN, G.B. OHANIAN

Slow flares in stellar aggregates and solar vicinity

M.A. MNATSAKANIAN, A.L. MIRZOYAN

A prediction of the flare activity of stellar aggregates

L. PIGATTO

Flare stars as age indicators in open clusters

V.V. HAMBARIAN, A.T. GARIBJANIAN, L.V. MIRZOYAN, A.L. MIRZOYAN

The relative number of flare stars in systems of different ages

121

K.R. LANG

Flare stars at radio wavelengths (Invited paper)

A.O. BENZ, M. GÜDEL, T.S. BASTIAN, E. FƯRST, G.M. SIMNETT, L. POINTON

Broadband spectral radio observations of flare stars

P.M. HEROUNI, V.S. OSKANIAN

Radio flare on eta Gemini star

R. PALLAVICINI, L. STELLA, G. TAGLIAFERRI

$X$-ray emission from solar neighbourhood flare stars

C.J. BUTLER

Balmer and soft X-ray emission from solar and stellar flares

J.P. CAILLAULT, S. ZOONEMATKERMANI

$\mathrm{X}$-ray variability in the Orion nebula

II. FLARE STARS AND RELATED OBJECTS. T TAURI STARS.

V.A. AMBARTSUMIAN

Some resolutions on T Tauri stars (Invited paper)

W. HERBST

The variability of $\mathrm{T}$ Tauri stars

G.V. ZAJTSEVA

Periodical variations of the brightness of $T$ Tauri

R.A. VARDANIAN

The polarization discovery and investigation of $\mathrm{T}$ Tau stars in Byurakan

P. BASTIEN, F. MÉNARD

Recent results on polarization of $T$ Tauri stars and other young stellar objects 
N.I. SHAKHOVSKAYA

The UBVRI photometric and polarimetric observations of the T Tau star HDE 283572

P.F. CHUGAINOV

Axial rotation of BY Dra-type stars and related objects

G.F. GAHM

Flares on T Tauri stars (Invited paper)

I. APPENZELLER

T Tauri stars and flare stars: common properties and differences

W. GÖTZ

Circumstellar phenomena and the position of $\mathrm{T}$ Tauri stars in the colour-magnitude diagram

P.P. PETROV

High resolution spectroscopy of RY Tauri: variability of the $\mathrm{Na} D$ line profiles

R.D. SCHWARTZ

Herbig-Haro phenomena associated with T Tauri: evidence for a precessing jet?

K. ISHIDA

Survey observations of emission line stars and Herbig-Haro objects at the Kiso Observatory

III. FLARE STARS AND RELATED OBJECTS.

FUORS AND OTHER NON-STABLE OBJECTS.

B. REIPURTH

FU Orionis eruptions and early stellar evolution (Invited paper)

L.G. GASPARIAN, A.S. MELKONIAN, G.B. OHANIAN, E.S. PARSAMIAN

Subfuors in Orion association

M.A. IBRAHIMOV, V.S. SHEVCHENKO

Slow flares and eruptive phenomena in early stages of stellar

evolution

H.M. TOVMASSIAN, R.Kh. HOVHANNESSIAN, R.A. EPREMIAN

A new fuor?

V.S. SHEVCHENKO, S.D. YAKUBOV

Correlation between flare stars and other populations in young clusters and star forming regions 
T.Yu. MAGAKIAN, T.A. MOVSESSIAN

The results of spectral observations of collimated outflows

L.I. MATVEYENKO

$\mathrm{H}_{2} \mathrm{O}$ megamaser in Orion $\mathrm{KL}$

I.V. GOSACHINSKIJ, N.A. YUDAEVA, R.A. KANDALIAN,

F.S. NAZARETIAN, V.A. SANAMIAN

Flares of radio line emission $\mathrm{H}_{2} \mathrm{O}$ in ori $\mathrm{A}$ and $\mathrm{W} 49 \mathrm{~N}$

R.L. GYULBUDAGHIAN, R.D. SCHWARTZ, L.F. RODRIGUEZ

On the connection between the IRAS point sources and galactic

nonstable objects

T.A. MOVSESSIAN

The statistical analysis of the optical and infrared luminosities of young stars

V. TSIKOUDI

Far infrared emission from post-T Tauri stars

J. KRELOWSKI, J. PAPAJ, W. WEGNER

Residual extinction effects in spectra of newly formed stars

IV. THEORETICAL PROBLEMS AND INTERPRETATION OF OBSERVATIONS.

V.P. GRININ

Review of the theoretical models of flares of the UV Ceti-type stars (Invited review)

E.R. HOUDEBINE, C.J. BUTLER

Quiescent chromospheric response to the (E)UV/optical flare

radiation field on dMe stars

E.A. BRUEVICH, M.A. LIVSHITS

The hydrogen atom kinetics in flare star chromospheres

M.M. KATSOVA

The Balmer decrement in red dwarfs spectra during the flares and quiescent state

J.G. DOYLE, G.H.J. VAN DEN OORD, C.J. BUTLER, T. KIANG

A model for the observed periodicity in the flaring rate

on YY Gem

V.S. HAYRAPETYAN, A.G. NIKOGHOSSIAN

Pinch-model of flares and its observational consequences 
H.A. HARUTYUNIAN, V.S. HAYRAPETYAN

On the gamma-activity of stellar flares

C.H. PAPAS

On a differential equation for electromagnetic wave transmission in flare stars and the possible existance of cohesive wave solutions

V.P. GRININ, A.S. MITSKEVICH

The stochastical approach to the modelling of the line profiles in $\mathrm{T}$ Tauri stellar winds

C.J. LADA

On the origin of dwarf stars (Invited review)

T. MONTMERLE

Magnetic activity and evolution of low-mass young stars

V. PROSPECTS FOR STELLAR FLARE RESEARCH AND CONCLUDING REMARKS.

M. RODONO

Prospects for studies of UV Cet-type flare stars (Invited review)

C.J. LADA

Closing remarks

Author index

Subject index

Object index 